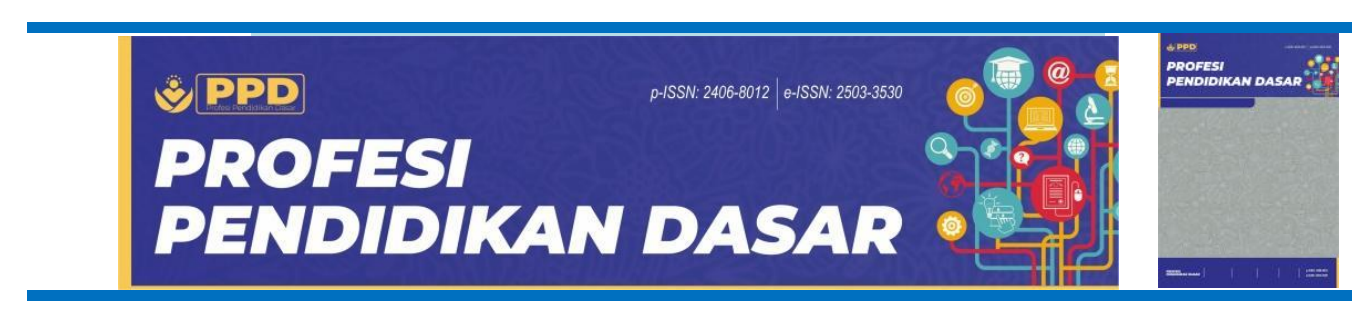

\title{
Connecting Spatial Reasoning Process to Geometric Problem
}

\author{
Lingga Nico Pradana* \& Octarina Hidayatus Sholikhah \\ Universitas PGRI Madiun, Madiun, Indonesia
}

*Email: nicopgsd@unipma.ac.id

\begin{tabular}{ll}
\hline \multicolumn{1}{c}{ Keywords: } & \multicolumn{1}{c}{ Abstract } \\
\hline spatial reasoning; & $\begin{array}{l}\text { The field of spatial reasoning has seen a lot of research. The process of spatial } \\
\text { reasoning, on the other hand, needs to be investigated further. The goal of } \\
\text { this study was to capture an elementary school student's spatial reasoning } \\
\text { process when solving geometric problems. The spatial skills used in solving } \\
\text { spatial skill } \\
\text { geometric problems were also identified in this study. A geometric test was } \\
\text { ghosen as the study's subjects based on their written responses. According to } \\
\text { the findings, the subject's spatial reasoning process always begins with the } \\
\text { processing of information in mental visualization. Mental visualization is used } \\
\text { to help with orientation and selecting the appropriate visual perspective. The } \\
\text { spatial skills of spatial visualization and spatial orientation are critical in } \\
\text { spatial reasoning. Furthermore, this research initiated the emphasis on the } \\
\text { focus of spatial reasoning in the process. }\end{array}$ \\
\end{tabular}

\section{INTRODUCTION}

\section{Background}

Spatial reasoning is an ability related to representing and using objects and relationships geometrically in two and three dimensions (Williams et al., 2010; Yüksel, 2017). Spatial reasoning has three main properties (NCTM, 2006). First, awareness of space such as distance, coordinates and dimensions. Some of these skills are explicitly discussed in the mathematics curriculum. Second, the interrelationship of spatial information representation, graphic coding and decoding such as diagrams and maps. Third, interpreting spatial information and making decisions.

When someone does spatial reasoning, then there are spatial skills that are used. Spatial skills are classified into five components, namely spatial perception, spatial visualization, mental rotation, spatial relations, and spatial orientation (Yüksel, 2017). Spatial perception is the ability to determine vertical and horizontal directions based on information. Spatial

(C) The Author(s). 2021

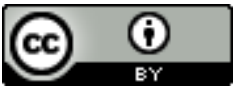

This work is licensed under a Creative Commons Attribution 4.0 International License 
visualization is the ability to describe situations based on information (Lowrie et al., 2017; Moore-Russo et al., 2013). Mental rotation is the ability to rotate two- or three-dimensional objects and imagine their position when rotated. Spatial relation is the ability to recognize relationships between parts of objects (Lowrie \& Jorgensen, 2017; Yüksel, 2017). Spatial orientation is the ability to enter a given spatial situation (Peng \& Sollervall, 2014).

\section{Problem of Study}

In this article, we carried out the student' spatial reasoning process in geometric problems. In previous research, spatial reasoning was stated as one of the factors that made someone successful in the field of mathematics (Kovačevi'c, 2017; Mulligan et al., 2017; Newcombe, 2013). Then it becomes another trigger for research to design spatial reasoning activities (Cheng \& Mix, 2014; Hartatiana et al., 2017; Lowrie et al., 2017). These activities designed to improve spatial reasoning and mathematics performance of elementary school students. However, research was mostly done on elementary school students. The research still hasn't highlighted the elementary school student' process of reasoning. In the measurement of spatial reasoning, the instruments used by previous studies are in the form of multiple choices. For example, Spatial Reasoning Instrument (SRI) (Ramful et al., 2017), paper folding tests (Akayuure et al., 2016; Williams et al., 2010), mental rotation test (Yoon \& Mann, 2017) etc. However, the spatial reasoning instrument has not described the spatial reasoning process itself.

\section{State of the Art}

In previous studies, not all components were used in measuring spatial reasoning. Lowrie et al (2017) using three components of spatial reasoning, namely spatial visualization, mental rotation and spatial orientation to design spatial reasoning activities. While Cheng \& Mix designing spatial training uses two components, mental rotation and spatial relation (Cheng \& Mix, 2014). It states that in spatial reasoning, not all spatial skills are used. But it is more directed to the problem presented can be solved using the appropriate spatial skills.

The research that has been done, on the other hand, has been more focused on quantifying spatial reasoning. There are still few studies that show how a person's spatial reasoning works. This inspires the researcher to investigate the process of spatial reasoning as it relates to the elements of spatial skills. As a result, the findings of this study can be applied to the spatial reasoning process itself.

\section{Gap Study \& Objective}

Spatial reasoning deals with geometric problems (Kovačevi'c, 2017). Geometric problems have the potential to make someone use spatial skills (Lane et al., 2018). Geometric problems have the potential to make someone use spatial skills (Yüksel, 2017). This provides an opportunity to obtain a spatial reasoning process that involves spatial skills on geometric problems. Studies on geometry are concentrated mainly on individual abilities and on processes. This ability includes manipulating various modes of object representation, recognizing and constructing nets, structuring object structures, recognizing object properties and comparing object shapes, and determining the volume and area of objects (Pittalis \& Christou, 2010). The scope of a geometrical problem is a twodimensional and three-dimensional object. Thus, the purpose of this study was to describe the elementary school students' spatial reasoning process in solving geometric problems. In the process, spatial skills are often used which are often used in solving problems and how much the spatial skills function for a solver. 


\section{METHOD}

\section{Type and Design}

This research is a qualitative case study research. The research focuses on spatial reasoning and the use of aspects of spatial reasoning in solving geometric problems. By describing the process of spatial reasoning, the explanation related to the process and the spatial abilities used can be identified as related.

\section{Data and Data Sources}

Participants in this study were 17 elementary school student in Madiun. More specifically, participants consisted of 6 male and 11 female and had an average age of 10,43 years. Participants are upper class of elementary school $(8$ students are grade four and 9 students are grade five). From the seventeen participants, 3 participants were taken as the research subjects (Subject A: grade five - Female; Subject B: grade five - Female; Subject C: grade four-Male). The research subjects were chosen based on the answers of participants who have the potential to provide data on the spatial reasoning process.

Table 1. Student Characteristic

\begin{tabular}{llllll}
\hline \multirow{2}{*}{ Source } & Grade & $\begin{array}{l}\text { N (by } \\
\text { Grade) }\end{array}$ & Gender & $\begin{array}{l}\text { N (by } \\
\text { Gender) }\end{array}$ & Average Age \\
\hline \multirow{2}{*}{ Participant } & Four & 8 & Male & 6 & 10,43 \\
& Five & 9 & Female & 11 & 1 \\
\cline { 3 - 6 } Subject & Four & 2 & Male & 1 & \multirow{2}{*}{10,78} \\
& Five & 1 & Female & 2 & \\
\hline
\end{tabular}

\section{Data Collection Technique}

The study began by giving geometric problems to the subjects (sample presented in Figure 1). The problem involved manipulating different two- or three-dimensional objects. The results of the participants' answers were analyzed to determine the research subjects. The selected research subjects were then interviewed to find out the spatial reasoning process carried out and identify the spatial skills used.

Interviews were conducted with participants who could potentially provide data on the spatial reasoning process. The selection criteria are based on participants' written performance on geometric problems that have been resolved. There were three subjects (1 male; 2 female) interviewed to identify the spatial reasoning process and the spatial skills used. The interview procedure is carried out in an unstructured and flexible manner for all indicators of geometry problems. If the subject does not write an explanation, then the question given leads to the subject's thoughts about the answer he wrote.

Findings were analyzed with two tools. First is the process of spatial reasoning based on the primary nature of spatial reasoning. The main properties in spatial reasoning are: (1) awareness of space, (2) the association of spatial information representation, (3) interpretation of spatial information and making decisions. The second is identifying spatial skills that are components of the subject in doing spatial reasoning for students. Spatial skills identified include (1) spatial perception, (2) spatial visualization, (3) mental rotation, (4) spatial relations, and (5) spatial orientation. 


\section{Data Analysis}

The spatial reasoning process of the subject required several analyzes. Interview transcripts are read and analyzed by researchers using the nature of spatial reasoning and the components of spatial skills. The researcher identifies each process carried out by the subject and maps the appropriate spatial skills components. Next, by adapting the nature of spatial reasoning, the researcher makes a cycle of the spatial reasoning process based on the spatial skills used in solving geometric problems.

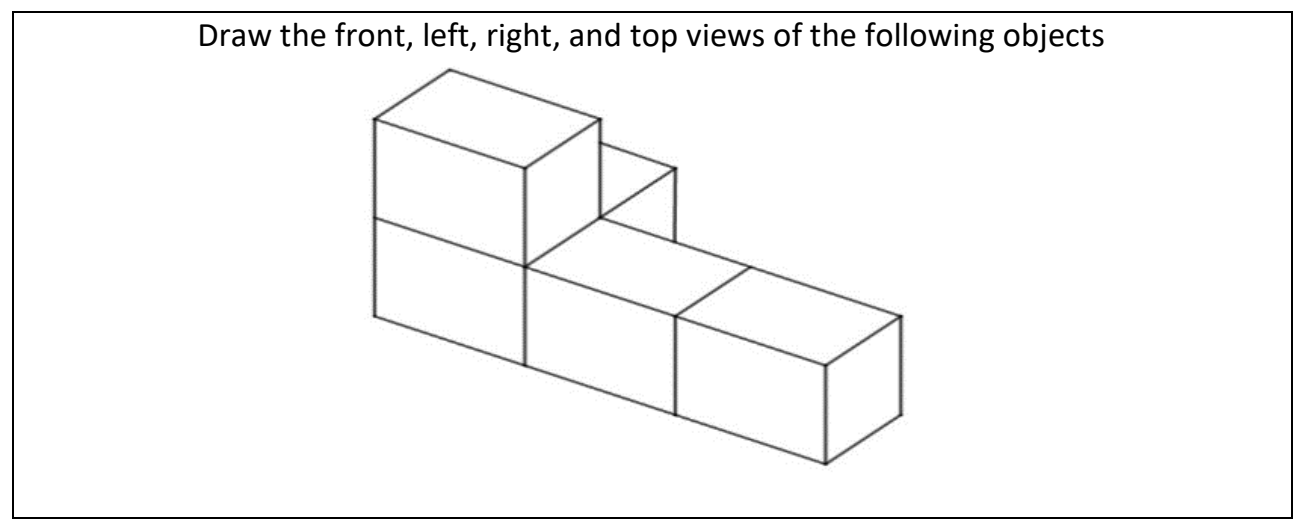

Figure 1: Geometric problem

\section{RESULT}

The results of this study are presented based on indicators of geometric problems. The data presented is the answer of the subject who has solved the geometrical problem given and the results of the interview that support the findings. The process of spatial reasoning and identification of spatial skills are presented based on the type of geometric problem. The problem of manipulating two- or three-dimensional objects is presented with the problem of moving isometric views to orthogonal views.

Based on Figure 2, the answers written by subject $A$ are drawn on a flat plane. The depiction of the front, left, and right sides in accordance with the orientation of the view given is orthogonal. However, the upper side of the image presented does not match the orientation. Then an interview was conducted to confirm the thoughts the subject carried out in solving the problem. From the results of the interview, the subject drew the front side by positioning itself in front of the object. The same thing is done for the left, right and top sides by positioning themselves on the left, right and top. When determining the left side, subject $A$ rotates the question paper so that the subject can see the left side can be seen clearly so that the subject gets a picture of the left side in accordance with his view. However, that also applies in determining the upper side. This changes the orientation of the upper side and makes the image rotate 90 degrees. So, the subject A make spatial visualization which included the spatial orientation process. The spatial orientation itself make subject $A$ reason about rotation and use mental rotation skill. 


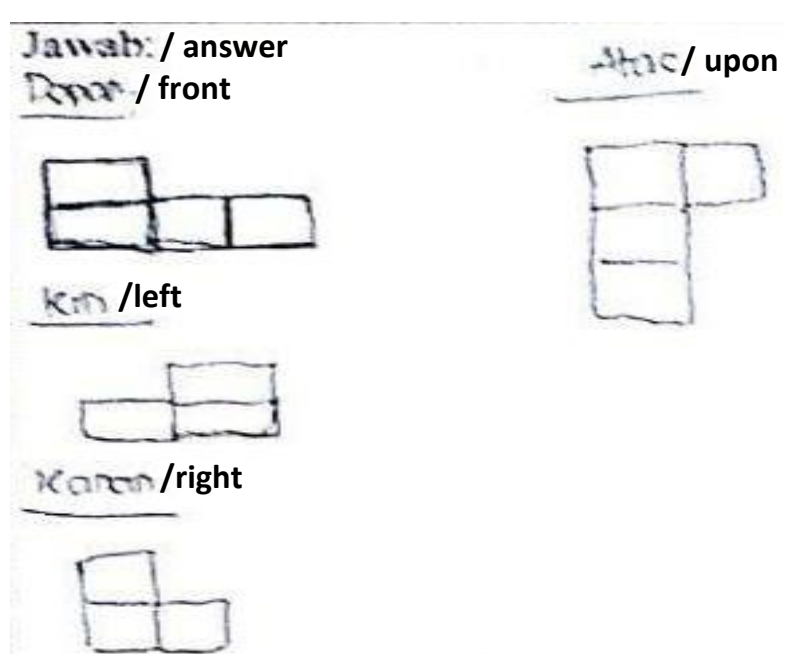

Figure 2: Answer of subject A
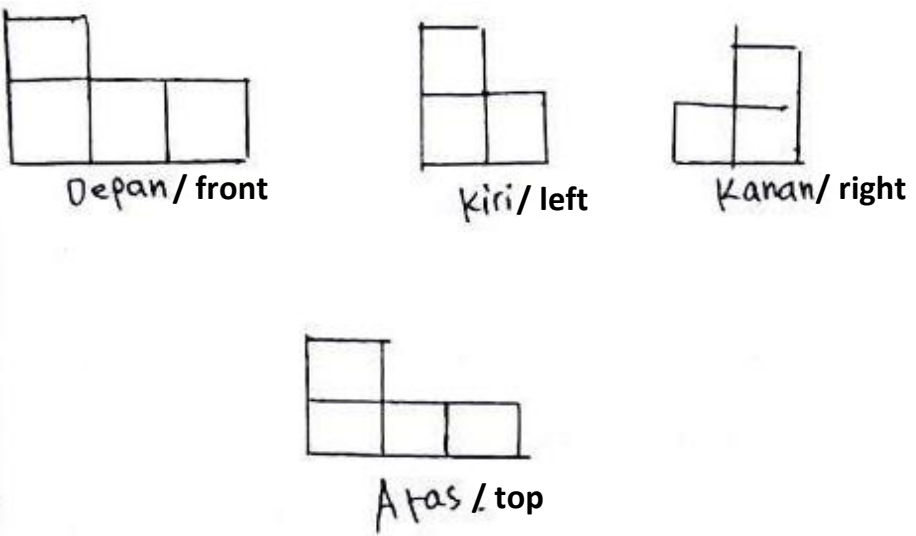

Figure 3: Answer of subject B

In Figure 3, Subject B can solve the problem correctly based on the answers provided. We inquired about the strategies employed in resolving these issues during the interview. Subject B completes the task by counting the numerous cubes first. The subject then confirms the placement of each cube in the arrangement and positions itself on the front, left, right, and top sides. The process of obtaining a side view by drawing the sides of the cube that are visible when positioning themselves in each direction was also confirmed. As a result of the spatial visualization process, subject $B$ presents the figure. In addition, the subject does so without turning the question paper. As a result, the subject's spatial visualization revealed a mental rotation process.

In Figure 4, Subject $C$ draws a side view based on the cubes' arrangement in the problem. This can be seen in the images on the left, right, and top, which are still in isometric view. The subject views the image based on the colors available on the problem, according to the results of interviews conducted on subject $C$. Subject $C$ is then required to draw one side in accordance with the cube arrangement's shape. Subject $C$ then notices that the image on the left is incorrect. According to Subject $C$, there should be three boxes. The shape of the left-hand view on subject $C$ was then confirmed. The cubes were arranged in the same way, and the results were the same. In the process of solving the geometric problem, the subject $C$ defines the perspective of spatial orientation. 


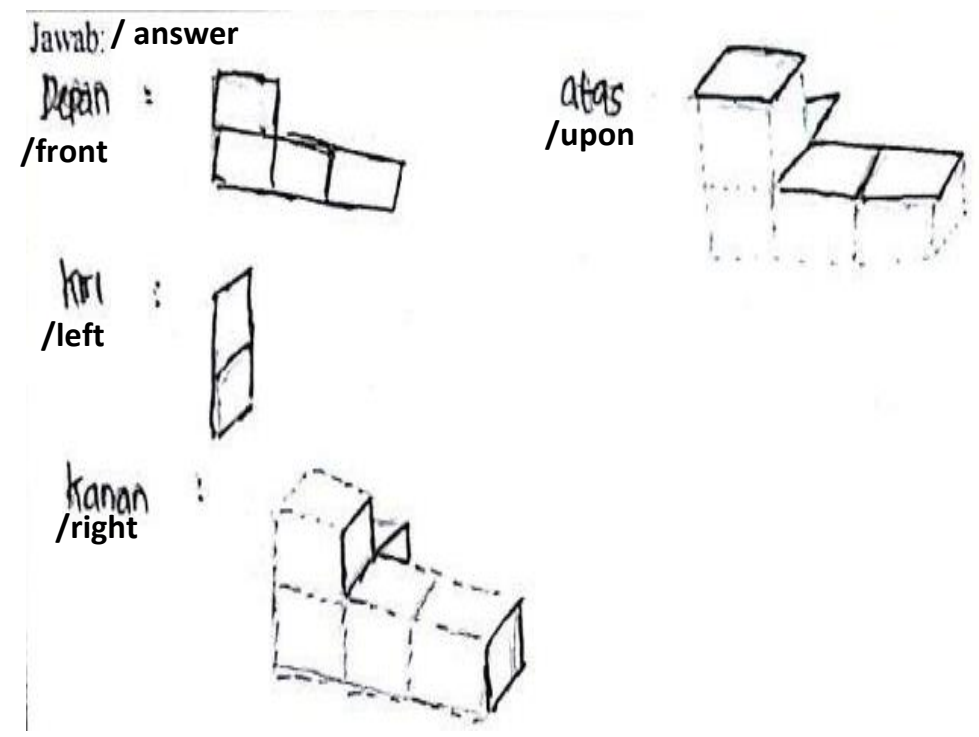

Figure 4: Answer of subject $C$

The research then identify the components of spatial skills that are used in the subject's spatial reasoning process. Subject $A$ and subject $B$ position their gaze to obtain a side view on the arrangement of the cubes. It proves that the subject uses spatial orientation in solving given problems. Then we asked why the left-hand side image was not skewed and the right-hand side image was unbroken. Each subject gives the same meaningful answer that is because it is viewed from the left side then what is seen is the front side of the 3 cubes so that the picture is not tilted. Then the explanation about the right side is because all the yellow sides are visible and only represent the yellow ones. We further asked whether the blue side was visible when viewed from the right direction. The subject responses were hidden by the blue side, which was horizontal and therefore not visible. The subject is able to recognize vertical and horizontal positions, so the spatial skills component used is spatial perceptions, according to the description.

\section{DISCUSSION}

According to research findings, the subject's spatial reasoning process always begins with the processing of information in mental visualization. The mental visualization then serves as the foundation for orienting yourself and selecting the appropriate visual perspective. Previous theories that support this finding state that visualization is very important in solving geometric problems (Jones et al., 2011; Moore-Russo et al., 2013). Then the process proceeds with forming a perspective to construct a solution. This is done to determine the views and orientation of the given object. This orientation serves as a benchmark to see objects from both an isometric and orthogonal view (Peng \& Sollervall, 2014; Pittalis \& Christou, 2010). After that there is a decision. This decision making refers to the possibility of a variety of perspectives in the spatial orientation process carried out in the spatial reasoning process (NCTM, 2006; van der Henst, 1999). Thus, the determination of new visualizations based on information and construction can be done in accordance with the problems given.

In the process of spatial reasoning, the influence of gender in this study is very pronounced. Yüksel (2017) states that gender is one of the factors that influence spatial 
reasoning. Male subjects in this study have a more flexible spatial orientation and can view objects from various angles. Previous research backs up the findings of this study, indicating that men as a group have better spatial reasoning abilities as a result of biological factors. (Gilligan et al., 2017; Smith, 2009; Tariq et al., 2013; Yoon \& Mann, 2017).

The use of spatial skills in solving geometric problems uses more spatial visualization and spatial orientation. Previous research has shown that visualization is frequently used in the solution of geometric problems. (Clements \& Battista, 1992; Tepylo, 2017; Walker et al., 2011). This demonstrates that paying attention to the process of spatial visualization and spatial orientation will increase the likelihood of success in solving geometric problems.

\section{CONCLUSION}

According to the findings of this study, spatial reasoning begins with the processing of information into mental visualization forms, the formation of perspectives to construct solutions, the making of decisions, and the determination of new visualizations and perspectives based on the current construction. The spatial skills of spatial visualization and spatial orientation are critical in spatial reasoning. In addition, this research establishes the importance of spatial reasoning in the process. The geometric problems used in this study have a limitation in that they do not force the subject to use spatial relation skills. As a result, previous research should first focus on issues involving spatial relationships. This research examines how students use spatial reasoning to solve geometric problems. Further research is needed to explore the constraints of spatial reasoning and provide assistance by detecting difficulties in the spatial reasoning process using the sequence of processes discovered.

Paying attention to the process of spatial reasoning is crucial in spatial reasoning. Spatial reasoning has a unique combination of the five spatial skills. Furthermore, all spatial abilities aid students in solving the geometric problem. As a result, teachers should think about paying attention to spatial reasoning, or at the very least, teachers should be able to create an activity, task, or problem based on spatial reasoning.

\section{REFERENCES}

Akayuure, P., Asiedu-Addo, K. S., \& Alebna, V. (2016). Investigating the Effect of Origami Instruction on Preservice Teachers' Spatial Ability and Geometric Knowledge for Teaching. International Journal of Education in Mathematics, Science and Technology, 4(3), 198-209. https://doi.org/10.18404/ijemst.78424

Cheng, Y. L., \& Mix, K. S. (2014). Spatial Training Improves Children's Mathematics Ability. Journal of Cognition and Development, 15(1), 2-11. https://doi.org/10.1080/15248372.2012.725186

Clements, D. H., \& Battista, M. T. (1992). Geometry and spatial reasoning. In D. Grouws (Ed.), Handbook of Research on Mathematics Teaching and Learning (pp. 420-464). National Council of Teachers of Mathematics.

Gilligan, K. A., Flouri, E., \& Farran, E. K. (2017). The contribution of spatial ability to mathematics achievement in middle childhood. Journal of Experimental Child Psychology, 163. https://doi.org/10.1016/j.jecp.2017.04.016

Hartatiana, Darhim, \& Nurlaelah. (2017). Student's Spatial Reasoning through Model Eliciting Activities with Cabri 3D. Journal of Physics: Conf. Series, 895, 1-5.

Jones, M. G., Gardner, G., Taylor, A. R., Wiebe, E., \& Forrester, J. (2011). Conceptualizing Magnification and Scale: The Roles of Spatial Visualization and Logical Thinking. Research in Science Education, 41(3), 357-368. https://doi.org/10.1007/s11165-010- 
9169-2

Kovačevi'c, N. K. (2017). Spatial reasoning in mathematics. International Scientific Colloquim Mathematics and Children Founded by Margita Pavleković, 6, 1-21.

Lane, D., Lynch, R., \& McGarr, O. (2018). Problematizing spatial literacy within the school curriculum. International Journal of Technology and Design Education, September. https://doi.org/10.1007/s10798-018-9467-y

Lowrie, T., \& Jorgensen, R. (2017). Equity and spatial reasoning: reducing the mathematical achievement gap in gender and social disadvantage. Mathematics Education Research Journal. https://doi.org/10.1007/s13394-017-0213-7

Lowrie, T., Logan, T., \& Ramful, A. (2017). Visuospatial training improves elementary students' mathematics performance. British Journal of Educational Psychology, 87(2), 170-186. https://doi.org/10.1111/bjep.12142

Moore-Russo, D., Viglietti, J. M., Chiu, M. M., \& Bateman, S. M. (2013). Teachers' spatial literacy as visualization, reasoning, and communication. Teaching and Teacher Education, 29(1), 97-109. https://doi.org/10.1016/j.tate.2012.08.012

Mulligan, J., Woolcott, G., Mitchelmore, M., \& Davis, B. (2017). Connecting mathematics learning through spatial reasoning. Mathematics Education Research Journal. https://doi.org/10.1007/s13394-017-0210-x

NCTM. (2006). Learning to Think Spatially. The National Academies Press. https://doi.org/10.17226/11019

Newcombe, N. S. (2013). Seeing relationships: Using spatial thinking to teach science, mathematics, and social studies. American Educator, 37(1), 26-32.

Peng, A., \& Sollervall, H. (2014). Primary school students' spatial orientation strategies in an outdoor learning activity supported by mobile technologies. International Journal of Education in Mathematics, Science and Technology, 2(4), 246-256.

Pittalis, M., \& Christou, C. (2010). Types of reasoning in 3D geometry thinking and their relation with spatial ability. Educational Studies in Mathematics, 75(2), 191-212. https://doi.org/10.1007/s10649-010-9251-8

Ramful, A., Lowrie, T., \& Logan, T. (2017). Measurement of Spatial Ability: Construction and Validation of the Spatial Reasoning Instrument for Middle School Students. Journal of $\begin{array}{lll}\text { Psychoeducational } \quad \text { Assessment, } & \text { 309-727), }\end{array}$ https://doi.org/10.1177/0734282916659207

Smith, N. J. (2009). Language Shift, Gender, and Ideologies of Modernity in Central Java, Indonesia. Journal of Linguistic Anthropology, 19(1), 57-77. https://doi.org/10.1111/j.1548-1395.2009.01019.x

Tariq, V. N., Qualter, P., Roberts, S., Appleby, Y., \& Barnes, L. (2013). Mathematical literacy in undergraduates: role of gender, emotional intelligence and emotional self-efficacy. International Journal of Mathematical Education in Science and Technology, 44(8), 1143-1159. https://doi.org/10.1080/0020739X.2013.770087

Tepylo, D. (2017). Examining Changes in Spatialized Geometry Knowledge for Teaching as Early Years Teachers Participate in Adapted ... (Issue July). https://doi.org/10.13140/RG.2.2.17795.60966

van der Henst, J. B. (1999). The mental model theory of spatial reasoning re-examined: the role of relevance in premise order. British Journal of Psychology (London, England: 1953), 90 ( Pt 1), 73-84. https://doi.org/10.1348/000712699161279

Walker, C. M., Winner, E., Hetland, L., Simmons, S., \& Goldsmith, L. (2011). Visual Thinking: 
Art Students Have an Advantage in Geometric Reasoning. Creative Education, 02(01), 22-26. https://doi.org/10.4236/ce.2011.21004

Williams, C., Gero, J., Lee, Y., \& Paretti, M. (2010). Exploring spatial reasoning ability and design cognition in undergraduate engineering students. Proceedings of the ASME Design Engineering Technical Conference, 6, 669-676. https://doi.org/10.1115/DETC2010-28925

Yoon, S. Y., \& Mann, E. L. (2017). Exploring the Spatial Ability of Undergraduate Students: Association With Gender, STEM Majors, and Gifted Program Membership. Gifted Child Quarterly, 61(4). https://doi.org/10.1177/0016986217722614

Yüksel, N. S. (2017). Visual-spatial Ability in STEM Education (M. S. Khine (ed.)). Springer. https://doi.org/10.1007/978-3-319-44385-0 